\title{
Bupivacaine decreases epidural meperidine requirements after abdominal surgery
}

Sophie St-Onge MD, François Fugère MD FRCPC, Michel Girard MD MHPE FRCPC

Purpose: The purpose of this study was to determine the optimal of three concentrations of bupivacaine $10.0 \%$. $0.05 \%, 0.10 \%)$ to add to an epidural infusion of meperidine $\left(1 \mathrm{mg} \cdot \mathrm{ml}^{-1}\right)$ for postoperative pain relief.

Methods: In this prospective, double blind study, 60 patients undergoing abdominal surgery with general anaesthes:a were randomized into three groups to receive for postoperative epidural analgesia: 1) $1 \mathrm{mg} \cdot \mathrm{ml}^{-1}$ meperidine (0\% group), 2) bupivacaine $0.05 \%$ and $\mid \mathrm{mg} \cdot \mathrm{ml}^{\prime}$ meperidine (0.05\% group), 3) bupivacaine $0.10 \%$ and I $\mathrm{mg} \cdot \mathrm{ml}^{-1}$ meperidine ( $0.10 \%$ group). Postoperatively, the epidural infusion rate was titrated to produce adequate analgesia and pain was assessed at rest and on movement.

Results: There were no differences in demographic data, average pain scores or side effects among the three groups. However. there was improvement of pain relief at rest over time in the three groups $(P<0.05)$ Postoperative epidural analgesic infusion rates increased over time for the three groups $(P<0.05)$ and were lower in the $0.10 \%$ group (mean of $10.0 \mathrm{ml} / \mathrm{hr}^{-1}$ ) than in the $0 \%$ group (mean of $\left.12.6 \mathrm{ml} \cdot \mathrm{hr}^{-1}\right)(P<0.05$ ). More than half of the $0 \%$ group had serum meperidine concentrations $>400 \mathrm{~g}^{-1}$ to control moderate postoperative pain.

Conclusion: Although analgesia was identical among groups, the lower serum concentrations of meperidine support the addition of bupivacaine $0.10 \%$ to meperidine when administered as a continuous infusion following abdominal surgery.

Objectif : Déterminer avec trois concentrations de bupivacaïne $(0,0 \%, 0,05 \%, 0,10 \%)$ ajoutées à une perfusion épidurale de mépéridine ( $1 \mathrm{mg} \cdot \mathrm{ml}$ '), la dose la plus efficace pour le soulagement de la douleur postopératoire.

Méthodes : Étude prospective en double aveugle. Soixante patients opérés pour une intervention abdominale sous anesthésie générale étaient répartis aléatoirement en trois groupes devant recevoir pour l'anaigésie postopératoire épidurale : 1) mépéridine $\mid \mathrm{mg} \cdot \mathrm{ml}^{\prime}\left(\right.$ (groupe $0 \%$ ), 2) bupivacaïne $0,05 \%$ et mépéridine $\mid \mathrm{mg}^{\prime} \mathrm{ml}^{-1}$ (groupe $0,05 \%$ ), 3) bupivacaine $0,10 \%$ et mépéridine $1 \mathrm{mg} \cdot \mathrm{mll}^{-1}$ (groupe $0,10 \%$ ). En postopératoire, la perfusion épidurale était réglée pour produire une analgésie adéquate et la douleur était évaluée au repos et en mouvement.

Résultats : II r'y avait pas de différences en rapport avec les données démographiques, les scores moyens de douleur et les effets secondaires entre les trois groupes. Cependant, la douleur au repos s'amenuisait avec le temps dans les trois groupes $(P<0.05)$. La vitesse des perfusions épidurales analgésiques augmentait avec le temps dans les trois groupes $(P<0,05)$ et était plus basse dans le groupe $0.10 \%$ (moyenne $10.0 \mathrm{ml} \cdot \mathrm{h}$ ') que dans le groupe $0 \%$ (moyenne $\left.12.6 \mathrm{ml} \cdot \mathrm{h}^{-1}\right)(P<0.05$ ). Plus de la moitié des sujets du groupe $0 \%$ avaient besoin de concentrations sériques $>400 \mu \mathrm{g} \cdot \mathrm{L}^{-1}$ pour le contrôle de la douleur modérée.

Conclusion : Bien que le niveau d'analgésie ait été identique pour les trois groupes, les concentrations inférieures de mépéridine justifient l'ajout de mépéridine $0,10 \%$ en perfusion continue après une intervention abdominale.

From the Département đ’anesthésie-réanimation, Hôpital Maisonncuve-Rosemont et Université de Montréal, Montréal, Québcc. Address correspondence to: Docteur François Fugère, Département d’ancsthésic-réanimation, Hốpital Norre-Dame, 1560 rue Sherbrooke Est, Montréal, Québec, H2L 4M1.

Supported, in part, by Faulding (Canada) Inc, Vaudreuil, Québec, and Nellcor Inc, Hayward, California.

Accepted for problication December 14, 1996. 
$\mathrm{T}$ HERE has been growing interest in providing postoperative analgesia for more than 20 yr. Epidural infusion has been increasingly popular since the publication of many reports demonstrating its superiority with regard to cardiovascular, pulmonary and gastro-intestinal postoperative complications. ${ }^{1-3}$

Since local anesthetics and opioids act by different mechanisms, their effects should be additive thus leading to a decreased requirement for each drug, thereby minimizing their individual side effects. However, the mechanism of action of lipid-soluble opioids is uncertain because serum concentrations when administered epidurally are similar to those obtained when given by intravenous or intramuscular routes. ${ }^{4,5}$ Although mixtures of bupivacaine and meperidine have been used previously, ${ }^{6-9}$ the optimum combination of the two drugs has not been determined.

Meperidine is an opioid of intermediate lipophilicity (partition coefficient of 38.8 , compared with morphine 1.4, fentanyl 813.0 and sufentanil 1778.0$)^{10}$ and has local anaesthetic activity. Alone, it has been used as a spinal ${ }^{11}$ as well as an epidural anaesthetic agent for surgery. ${ }^{12}$ These properties and its low cost, make it attractive for postoperative epidural analgesia.

The purpose of this study was to determine the optimal of three concentrations of bupivacaine $(0.0 \%$, $0.05 \%, 0.10 \%)$ to add to an epidural infusion of meperidine ( $\mathrm{l} \mathrm{mg} \cdot \mathrm{ml}^{-1}$ ) and to determine if side effects and serum concentrations of meperidine with the bupivacaine-meperidine mixtures were different from those with an epidural infusion of meperidine alone.

\section{Methods}

This randomized double blind study was carried out after the approval of the institution's ethics and research committees. Each patient gave written informed consent. During the study, all ASA physical status I-III patients undergoing elective abdominal surgery, either vascular or bowel resection surgery, requiring a midline incision, who had agreed to receive postoperative epidural analgesia were considered eligible. Patients $<18$ yr or $>75 \mathrm{yr},>100 \mathrm{~kg}$, those with preexisting neurological deficit or psychiatric disorder, allergy to the study drugs or history of drug abuse were ineligible.

All patients received premedication with 1-2 $\mathrm{mg}$ lorazepam sl $90 \mathrm{~min}$ before anaesthesia that was induced with 4-7 mg. $\mathrm{kg}^{-1}$ thiopentone, $3 \mu \mathrm{g} \cdot \mathrm{kg}^{-1}$ fentanyl and maintained with nitrous oxide and isoflurane. Fentanyl was allowed up to a maximum of $10 \mu \mathrm{g} \cdot \mathrm{kg}^{-1}$ and no opioid was administered during the last hour of the operation. Tracheal intubation was facilitated with $0.05 \mathrm{mg} \cdot \mathrm{kg}^{-1} \mathrm{~d}$-tubocurarine followed by $1.5-2 \mathrm{mg} \cdot \mathrm{kg}^{-1}$ succinylcholine and muscle relaxation was maintained with vecuronium as required.

In the operating room, after routine monitoring and $i v$ placement and before induction of anaesthesia, an epidural catheter was inserted at the level of T10-Tl1, Tl1-T12 or Tl2-Ll. Its position was confirmed by a dose of $5 \mathrm{ml}$ lidocaine $1.5 \%$ with adrenaline $1: 200,000$ and the presence of a sensory block was identified with ice before proceeding with general anaesthesia. Each patient was randomly assigned to one of three treatment groups: (1) $1 \mathrm{mg} \cdot \mathrm{ml}^{-1}$ meperidine without bupivacaine ( $0 \%$ group), (2) $1 \mathrm{mg} \cdot \mathrm{ml}^{-1}$ meperidine with bupivacaine $0.05 \%$ (0.05\% group), (3) $1 \mathrm{mg} \cdot \mathrm{ml}^{-1}$ meperidine with bupivacaine $0.10 \%(0.10 \%$ group). The infusion solution was prepared by the hospital pharmacy and the anaesthetist and investigator were blinded to which solution was used. Upon initiation of wound closure, the patients received an epidural bolus of $10 \mathrm{ml}$ of the study solution followed immediately by a continuous infusion of $8 \mathrm{ml} \cdot \mathrm{hr}^{-1}$.

Analgesia was assessed using a visual analog scale (VAS: $0=$ no pain up to $10=$ worst pain ever). The rate of the epidural infusion was adjusted according to the patient's pain assessment. If, at anytime, the VAS was $\geq 4 / 10$, an epidural bolus dose of $5 \mathrm{ml}$ solution was given and the infusion was then increased by 2 $\mathrm{ml} \cdot \mathrm{hr}^{-1}$. If, at anytime following recovery room departure, the pain score was $\leq 1 / 10$ and/or the patient was drowsy (sedation scale $\geq 3$ ) or respiratory frequency $<10 \cdot \mathrm{min}^{-1}$, the infusion was decreased by $2 \mathrm{ml} \cdot \mathrm{hr}^{-1}$. If a patient complained of severe pain despite an infusion rate as high as $22 \mathrm{ml} \cdot \mathrm{hr}^{-1}$, catheter dislodgment was excluded by physical examination and/or testing with lidocaine $2 \%$ with adrenaline $1: 200,000$ and the analgesic technique was changed.

Postoperatively, data were collected for $48 \mathrm{hr}$ divided into $12 \mathrm{hr}$ periods. Respiratory rate and somnolence were monitored hourly, and blood pressure and heart rate every four hours. Patients received oxygen at the discretion of the attending anaesthetist or surgeon. Oxygen saturation was continuously measured with a Nellcor $\mathrm{N}$ 200 pulse oximeter using a Nellcor D-25 Adult Digit Oxygen transducer placed on the finger. The $\mathrm{SpO}_{2}$ data were not accessed by attending staff and, therefore, were not used to modify oxygen administration. An episode of desaturation was defined as two consecutive measurements of $\mathrm{SpO}_{2}<90 \%$ of at least one minute.

Analgesia was assessed by evaluation of VAS at rest every hour and with movement (sitting up) twice a day. The total volume of analgesic solution administered 
during each of the $12 \mathrm{hr}$ of the $48 \mathrm{hr}$ of the study was noted as well as the number of epidural boluses of the tested solution.

Side effects were assessed twice daily for $48 \mathrm{hr}$ with the following scales: somnolence ( $\mathrm{l}=$ oriented and initiates conversation, $2=$ occasionally drowsy, $3=$ frequently drowsy, easy to arouse, $4=$ sleepy, responds to pain only, $5=$ unresponsive), nausea, vomiting and pruritus $(1=$ none, $2=$ mild, no treatment required, $3=$ moderate, treatment effective, $4=$ severe, treatment not effective). Sensory loss was determined with ice and motor blockade by using a modified Bromage scale $^{13}$ (for each leg: $0=$ able to raise extended leg off bed, $1=$ able to flex knee and ankle, $2=$ able to dorsiflex ankle only, 3 = unable to flex hip, knee or ankle; the score for each leg was added to give a possible maximum score of 6). Side effects were considered present when the following values were attained: sedation $\geq 3$, nausea, vomiting and pruritus $\geq 2$ and motor blockade $\geq 1$. Postural hypotension was considered to be present if blood pressure decreased $>30 / 20$ $\mathrm{mmHg}$ upon sitting. ${ }^{14}$ Finally, the delay after surgery until oral fluids were tolerated was noted. Urinary retention was not studied because all patients had a urinary catheter.

Blood for gas analysis was sampled every morning if an arterial line was present. Venous samples for measurement of serum meperidine and normeperidine concentrations were also taken in the morning of the first and second postoperative days. Samples were centrifuged and stored at $-20^{\circ} \mathrm{C}$ until analysis were performed at the Centre de toxicologie du Québec using a Hewlett Packard 5890 GC gas chromatographer equipped with a split injector on dual capillary columns and two nitrogen-phosphorus detectors. Products are recognized by a system of retention index. Calibration was linear between 100 and 1000 $\mu \mathrm{g} \cdot \mathrm{L}^{-1}$ for meperidine ( $\left.\mathrm{R}=0.9997\right)$ with a detection limit of $10 \mu \mathrm{g} \cdot \mathrm{L}^{-1}$. Normeperidine was not quantitated, the detection limit on this system is $500 \mu \mathrm{g} \cdot \mathrm{L}^{-1}$. Derivatization would be required to reach adequate sensitivity.

In common with Badner, ${ }^{15}$ we believe that a difference in the VAS of 2 or in the epidural infusion rate of $2 \mathrm{ml} \cdot \mathrm{hr}^{-1}$ would be necessary to warrant using the bupivacaine-meperidine combination. Considering the standard deviation for both measurements, a sample size of 20 patients per group was considered sufficient. ${ }^{16}$ Demographic comparisons were made using unpaired Student's $t$ test for parametric data and chi square analysis for nonparametric data. Pain scores, infusion rates, blood gas and oxygen saturation results were compared using two-factor ANOVA for repeated measures. Side-effects were compared by a log linear technique. $P<0.05$ was considered significant.

\section{Results}

Sixty patients were enrolled in the study. There were no differences in age, weight, sex or surgery distribution among the groups (Table I). All patients in the vascular group had an aorto-bifemoral bypass, while all in the digestive group had a bowel resection. One patient was excluded because of complications unrelated to the investigation in the immediate postoperative period. Six patients did not complete the study but each $12 \mathrm{hr}$ of completed data was kept for analysis. Of the six patients, one had the technique interrupted because of surgical complications (haemorragic shock), two had epidural catheter dislodgment and three (two in the $0 \%$ and one in the $0.10 \%$ group) did not complete the $48 \mathrm{hr}$ because of unsatisfactory analgesia in spite of a well positioned catheter.

Average pain scores at rest and upon movement for each $12 \mathrm{hr}$ varied between 0.7 and 2.4 at rest, and 3.9 and 5.7 upon movement (P:NS) (Figures 1 and 2).

TABLE I Demographic data

\begin{tabular}{lccc}
\hline & $\begin{array}{c}\text { Group 0\% } \\
(n=19)\end{array}$ & $\begin{array}{c}\text { Group 0.05\% } \\
(n=20)\end{array}$ & $\begin{array}{c}\text { Grousp 0.10\% } \\
(n=20)\end{array}$ \\
\hline Age (yr) & $59 \pm 11$ & $58 \pm 112$ & $56 \pm 11$ \\
Weight (kg) & $70 \pm 12$ & $70 \pm 12$ & $74 \pm 16$ \\
Sex (M/F) & $11 / 8$ & $13 / 7$ & $13 / 7$ \\
ASA I (n) & 0 & 1 & 6 \\
ASA II (n) & 12 & 10 & 8 \\
ASA III (n) & 7 & 9 & 6 \\
Surgery & & & \\
$\quad$ Vascular/alimentary, $n)$ & $14 / 5$ & $13 / 7$ & $13 / 7$ \\
\hline
\end{tabular}

Mean \pm SD

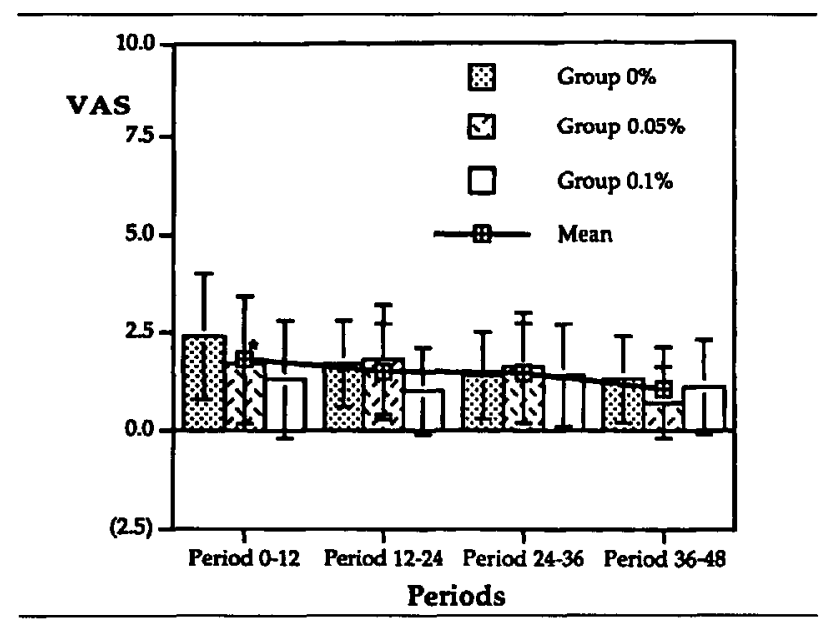

FIGURE 1 VAS at rest

${ }^{\star} P<0.02$ for mean of VAS score over rime. VAS among groups: NS. 


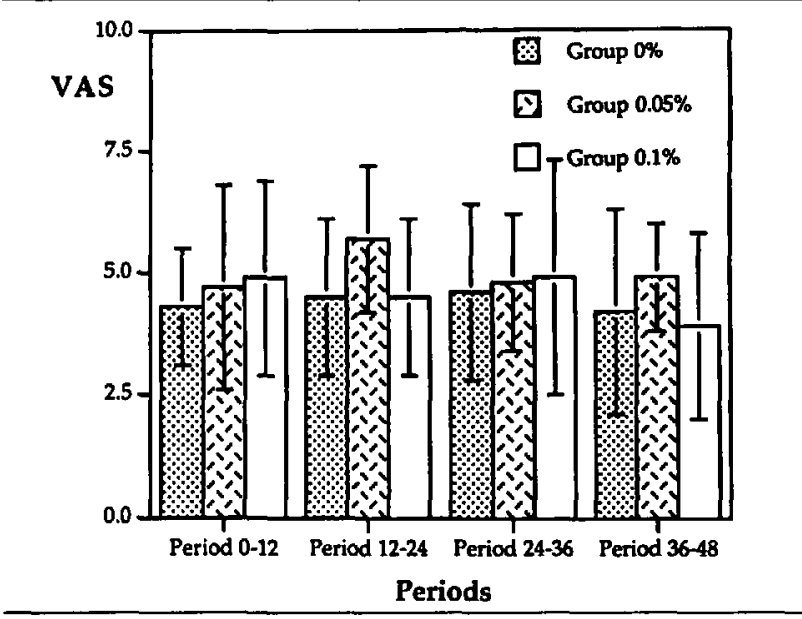

FIGURE 2 VAS with movement

However, there was an improvement of pain relief at rest over $48 \mathrm{hr}$ in all three groups $(P<0.02)$. The average infusion rates varied between 9.1 and $13.5 \mathrm{ml} \cdot \mathrm{hr}^{-1}$ (Figure 3 ) and it was lower $(P<0.05)$ for the whole period in the $0.10 \%$ group (average of $10.0 \mathrm{ml} \cdot \mathrm{hr}^{-1}$ ) than in the $0 \%$ group (average of $12.6 \mathrm{ml} \cdot \mathrm{hr}^{-1}$ ). In addition, infusion rates increased $(P<0.0001)$ over time for the three groups.

There were no differences among the groups for the incidence or severity of side effects as assessed by the different scales (Table II). All motor blockade was mild, modified Bromage scale of 1 , with the exception of one patient in the $0.10 \%$ group who had a modified Bromage scale of 2 associated with numbness of the affected limb. Decreased sensation to ice was documented in a similar number of patients in the three groups ( 12 in $0 \%$ group, 15 in $0.05 \%$ group and 18 in $0.10 \%$ group, NS). Two patients had hypotension associated with hypovolaemia, one in the $0 \%$ group and one in the $0.05 \%$ group. One patient in the $0 \%$ group had orthostatic hypotension, that was associated with a high infusion rate (average of $19.2 \mathrm{ml} \cdot \mathrm{hr}^{-1}$ for the whole period). There was no difference in the number of patients given oxygen nor in the percentage of time desaturation was present for each period. When blood gases were measured there was no difference in arterial saturation compared with the pulse oximeter readings. No patient experienced severe desaturation $\left(\mathrm{SpO}_{2}\right.$ $<80 \%$ ), respiratory depression or had any major complications related to the analgesia technique.

Meperidine serum concentrations were higher in all groups on the second day than on the first day $(P \leq 0.0001$, Figure 4$)$. On the first postoperative day, concentrations were higher in group $0 \%(353 \pm$ $\left.31 \mu \mathrm{g} \cdot \mathrm{L}^{-1}\right)$ than in group $0.05 \%\left(248 \pm 29 \mu \mathrm{g} \cdot \mathrm{L}^{-1}\right.$, $P<0.02)$ or in group $0.1 \%\left(236 \pm 30 \mu \mathrm{g} \cdot \mathrm{L}^{-1}, P<0.02\right)$.

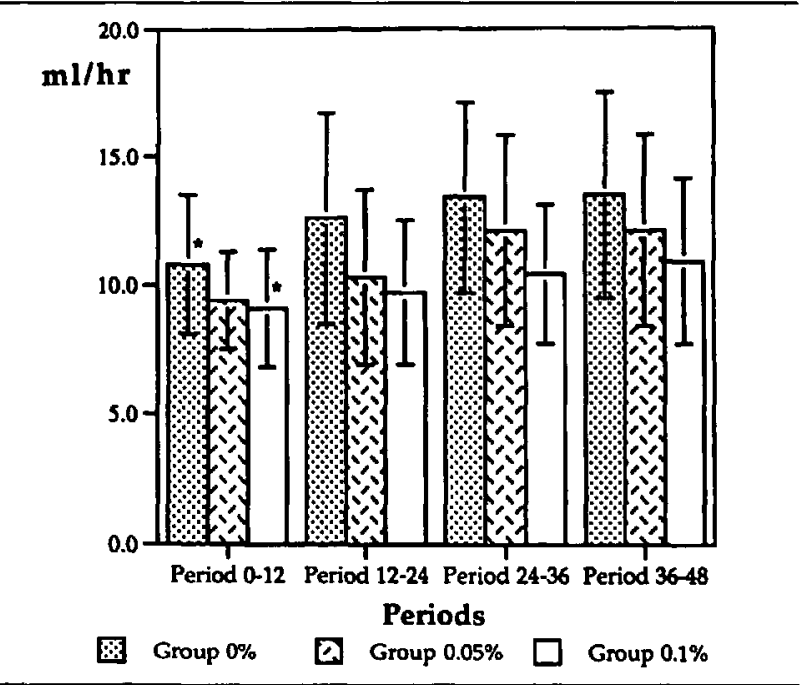

FIGURE 3 Average infusion rate

Infusion rate increased over time for each group $(P<0.0001)$

* For each period, mean infusion rate of group $0.1 \%$ was lower than mean infusion rate of group $0 \%(P<0.05 \%)$

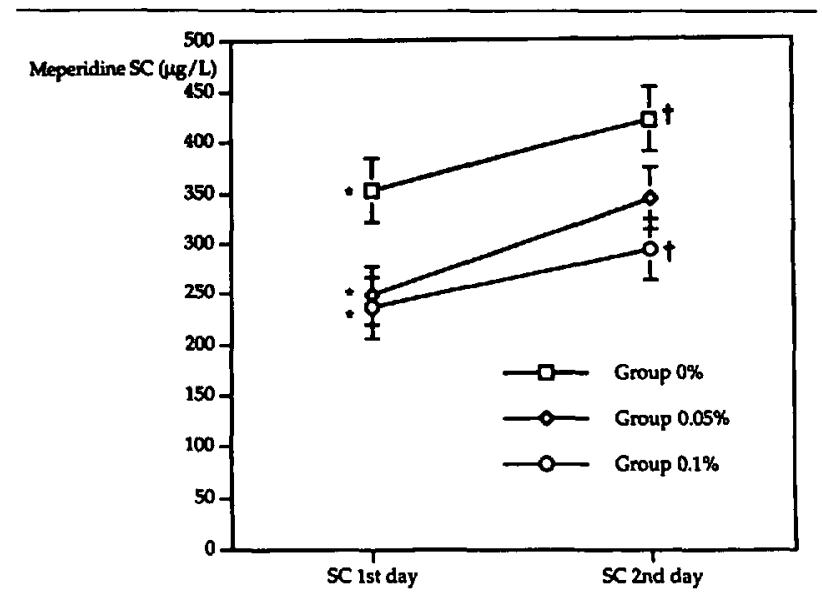

FIGURE 4 Serum concentrations of meperidine on the first and second postoperative day (mean \pm SEM)

For each group, serum concentration on the second day was higher than on the first $(P<0.0001)$

* Group $0 \%$ higher than group $0.05 \%$ and group $0.1 \%(P<0.02)$

$\dagger$ Group $0 \%$ higher than group $0.1 \%(P<0.01)$

TABLE II Side effects

\begin{tabular}{lccc}
\hline & $\begin{array}{c}\text { Group 0\% } \\
(n=19)\end{array}$ & $\begin{array}{c}\text { Group 0.05\% } \\
(n=20)\end{array}$ & $\begin{array}{c}\text { Grout 0.10\% } \\
(n=20)\end{array}$ \\
\hline Motor block & 0 & 1 & 4 \\
Nausea/vomiting & 8 & 11 & 10 \\
Pruritus & 3 & 2 & 2 \\
Orthostatic hypotension & 1 & 0 & 0 \\
Sedation & 2 & 8 & 6 \\
Hypoxia $\left(\mathrm{SpO}_{2}<90 \%\right)$ & 6 & 8 & 6 \\
Respiratory depression & 0 & 0 & 0 \\
\hline
\end{tabular}


On the second day, concentrations were higher in group $0 \%\left(421 \pm 32 \mu \mathrm{g} \cdot \mathrm{L}^{-1}\right)$ than in group $0.1 \%$ $\left(293 \pm 31 \mu \mathrm{g} \cdot \mathrm{L}^{-1}, P<0.01\right)$.

The delay before patients could tolerate a liquid diet was $4.3 \pm 2.0$ days (mean $\pm S D$ ) for the group $0 \%$, $4.0 \pm 1.6$ days for the group $0.05 \%$ and $3.7 \pm 1.1$ days for the group $0.10 \%(\mathrm{NS})$.

\section{Discussion}

Our study showed that bupivacaine $0.1 \%$ decreased epidural meperidine requirements after abdominal surgery. The addition of bupivacaine did not influence the incidence of side effects nor the return of gastrointestinal function. There was considerable absorption of meperidine into the systemic circulation with the meperidine only epidural solution.

With the increasing popularity of epidural analgesia, many agents have been studied in the search for the ideal combination. In labour pain, a combination of very low doses of bupivacaine and epidural opioids has been used with success. ${ }^{17}$ However, higher concentrations of local anaesthetics seem necessary with epidural opioid infusion for postoperative analgesia. The addition of bupivacaine $0.125 \%{ }^{18}$ but not bupivacaine $0.1 \%{ }^{15}$ to epidural fentanyl $10 \mu \mathrm{g} \cdot \mathrm{ml}^{-1}$ ameliorated pain relief after abdominal or thoracic surgery. Although epidural administration of a mixture of bupivacaine and meperidine has been reported, ${ }^{8,19}$ few have tried to determine the optimal concentration of bupivacaine to add to meperidine., 9,20

Epidural meperidine has been administered previously as a continuous infusion at a concentration of 1 to $2.5 \mathrm{mg} \cdot \mathrm{ml}^{-1}{ }^{19}$ or by bolus at a concentration of $4^{21}$ or $10^{22} \mathrm{mg} \cdot \mathrm{ml}^{-1}$. The meperidine and bupivacaine concentrations in our study were in the range recommended by Ferrante ${ }^{3}$ and reflect our clinical practice.

Infusion rates were lower with the addition of bupivacaine $0.10 \%$ to epidural $1 \mathrm{mg} \cdot \mathrm{ml}^{-1}$ meperidine. This did not provide better analgesia at rest or with movement or fewer side effects, probably because we adjusted the infusion rate of the solution. Two studies have evaluated the effect of changing bupivacaine concentration in a bupivacaine-meperidine epidural solution. However, the population of patients and the design of the studies were different from ours. In the first, ${ }^{9}$ the solution was given as a bolus for labor pain relief and showed no difference in pain score between bupivacaine $0.125 \%, 0.1875 \%$ and $0.25 \%$ when combined with epidural $2.5 \mathrm{mg} \cdot \mathrm{ml}^{-1}$ meperidine. The second was the only study ${ }^{24}$ in which attempts were made to determine the ideal combination of bupivacainemeperidine for postoperative analgesia. The authors reached similar conclusions: addition of bupivacaine $0.01 \%$ or $0.10 \%$ to $1 \mathrm{mg} \cdot \mathrm{ml}^{-1}$ meperidine did not improve pain relief. However, the surgery was different (thoracotomy), NSAIDs were administered to all patients and patient controlled epidural analgesia (PCEA) was used to titrate the optimal dose.

The pain relief obtained with epidural meperidine in our study is in agreement with previous reports of its analgesic efficacy for labour pain ${ }^{6,8,25-27}$ and for post-cesarean, ${ }^{7,21}$ low-abdominal ${ }^{7}$ and thoracic ${ }^{28}$ surgical pain. Mean hourly meperidine consumption, reported in the literature, ranges from 5 to 20 $\mathrm{mg} \cdot \mathrm{hr}^{-1}$, the lowest doses being with the use of PCEA. However, comparison with our study is difficult because the surgical procedures were different. Nevertheless, the average pain scores are equivalent to those reported in previous studies with epidural meperidine ${ }^{21,22}$ and with other opioids. ${ }^{15,18,29}$

The incidence of side effects is comparable with that reported in other studies. The incidence of pruritus is similar to that reported with epidural meperidine administration ${ }^{7,22}$ but lower than the incidence reported with other opioids. ${ }^{29,30}$ The incidence of nausea and vomiting is in the range reported in the literature (between $9 \%$ and $50 \%$ ). Any comparisons are difficult because the operations were different and did not involve major surgery or bowel surgery as in our study.

Despite a recent trial ${ }^{31}$ showing that meperidine administered by the intramuscular or the epidural route should be considered a risk factor for confusion in older patients, no such episode occurred in our study. However, our patient population was younger (average of 58 yr compared with 73 yr). As suggested previously, meperidine should be used with caution in the elderly and in patients at risk for delirium.

The principal mechanism of action of epidural meperidine is controversial. Cousins ${ }^{32}$ reported postoperative pain relief in non-pregnant patients with $100 \mathrm{mg}$ epidural meperidine. He attributed it to a selective spinal action of meperidine. Glynn, ${ }^{33}$ after demonstrating an absence of sympathetic blockade with epidural meperidine administered for cancer pain relief, concluded that the dorsal horn was the major site of action and was distinct from the conduction blockade produced by local anesthetics, thus indicating a "selective" spinal mechanism of analgesia. On the contrary, Husemeyer ${ }^{25}$ noting hypoalgesia to pinprick combined with high serum meperidine concentrations attributed its local anaesthetic properties and the mechanism of action of epidural meperidine to a systemic effect. In our study, plasma concentrations of meperidine obtained with epidural infusions did not allow us to exclude a systemic effect 
as the main mechanism of action as has been reported for more liposoluble opioids. ${ }^{4}$ During the highest infusion rates, more than half of the meperidine only group had concentrations, at some time, $>400$ $\mu \mathrm{g} \cdot \mathrm{L}^{-1}$; concentrations sufficient to control moderate postoperative pain. ${ }^{34}$

The epidural infusion rate increased over time in the three groups. As this occurred together with improved analgesia at rest, it could indicate a bias in the protocol that encouraged an increase in infusion in response to pain rather than a decrease when the patient was painless. Secondly, tachyphylaxis may have occurred but, although reported with epidural bolus injection ${ }^{35}$ or continuous infusion ${ }^{36}$ of local anaesthetics, it has never been reported with epidural meperidine. On the contrary, tachyphylaxis has been shown to be prevented by the addition of an opioid to a local anaesthetic administered epidurally. ${ }^{37,38}$ Thirdly, with time the patients may have greater mobility with increased pain stimuli and higher analgesic needs. This increase of epidural infusion rate over time has been reported before. ${ }^{23}$

This is the first study that attempted to establish the benefits of combining bupivacaine and meperidine for postoperative analgesia in a continuous epidural infusion. It has been suggested ${ }^{39}$ that the opioid-sparing effect of NSAIDs could decrease the incidence of side effects but this hypothesis still has to be tested with the epidural bupivacaine-meperidine combination. A reduction of side effects was not observed in our study despite lower serum concentrations of meperidine when bupivacaine was added to epidural meperidine infusion. However, our study was not sufficiently powerful to detect any difference in the incidence of side effects. We believe that the addition of bupivacaine to epidural meperidine is warranted because of the decreases in infusion rate and in serum meperidine concentrations with bupivacaine $0.10 \%$.

In conclusion, the addition of bupivacaine $0.10 \%$ did allow a reduction in the administered doses of meperidine. Although analgesia and the incidence of side effects were identical, the lowest serum concentrations of meperidine support the addition of bupivacaine to meperidine when administered as an epidural infusion following abdominal surgery.

\section{Acknowledgments}

The authors wish to thank Mrs. Christiane Côté BSc Inf for her help in the data collection, Mr. Michel Lefebvre MSc of the Centre de toxicologie du Québec for the plasma meperidine determination and $\mathrm{Mr}$. Peter Ross Ph.D. for processing the samples.

\section{References}

1 Modig J. Lumbar epidural nerve blockade versus parenteral analgesics. Acta Anesthesiol Scand 1978; 70 (Suppl): $30-5$.

2 Rawal N, Sjöstrand U, Christoffersson E, Dahlström $B$, Arvill $A, R y d m a n ~ H$. Comparison of intramuscular and epidural morphine for postoperative analgesia in the grossly obese: influence on postoperative ambulation and pulmonary function. Anesth Analg 1984; 63: 583-92.

3 Yeager MP, Glass DD, Neff RK, Brinck-Johnsen T. Epidural anesthesia and analgesia in high-risk surgical patients. Anesthesiology 1987; 66: 729-36.

4 Loper KA, Ready LB, Downey $M$, et al. Epidural and intravenous fentanyl infusions are clinically equivalent after knee surgery. Anesth Analg 1990; 70: 72-5.

5 Bouchard $F$, Drolet $P$. Thoracic versus lumbar administration of fentanyl using patient-controlled epidural after thoracotomy. Reg Anesth 1995; 20: 385-8.

6 Baraka A, Maktabi M, Noueihid R. Epidural meperidine-bupivacaine for obstetric analgesia. Anesth Analg $1982 ; 61: 652-6$.

7 Brownridge $P$, Frewin $D B$. A comparative study of techniques of postoperative analgesia following Caesarean section and lower abdominal surgery. Anaesth Intensive Care 1985; 13: 123-30.

8 Brownridge P. Epidural bupivacaine-pethidine mixture. Clinical experience using a low-dose combination in labour. Aust NZ J Obstet Gynaecol 1988; 28: 17-24.

9 Handley $G$, Perkins $G$. The addition of pethidine to epidural bupivacaine in labour- effect of changing bupivacaine strength. Anaesth Intensive Care 1992; 20: 151-5.

10 Cousins $M$, Cherry D, Gourlay G. Acute and chronic pain: use of spinal opioids. In: Cousins MJ, Bridenbaugh PO (Eds.). Neural Blockade in Clinical Anesthesia and Management of Pain, 2nd ed. Philadelphia: J.B.Lippincott Co., 1988: 955-1029.

11 Patel D, Janardhan $Y$, Merai B, Robalino J, Shevde $K$. Comparison of intrathecal meperidine and lidocaine in endoscopic urological procedures. Can J Anaesth 1990; 37: 567-70.

12 Kaza $R$, Lawlor M, Allen W, Ranella L, Johnson C. Epidural meperidine provides surgical anesthesia for critically ill patients undergoing major surgery (Letter). Anesth Analg 1993; 77: 1084.

13 Katz JA, Bridenbaugh PO, Knarr DC, Helton SH, Denson $D D$. Pharmacodynamics and pharmacokinetics of epidural ropivacaine in humans. Anesth Analg 1990; 70: 16-21.

14 Richardson EP, Beal MF, Martin JB. Degenerative diseases of the nervous system. In: Braunwald $E$, Isselbacher E, Petersdorf R, Adams R, Wilson J (Eds.). 
Harrison's Principle of Internal Medicine, 11 th ed.

New York: McGraw Hill, 1987: 2011-27.

15 Badner NH, Komar WE. Bupivacaine 0.1\% does not improve post-operative epidural fentanyl analgesia after abdominal or thoracic surgery. Can J Anaesth 1992; 39: 330-6.

16 Lerman J. Study design in clinical research: sample size estimation and power analysis. Can J Anaesth 1996; 43: 184-91.

17 Chestnut DH, Owen CL, Bates JN, Ostman LG, Choi $W W$, Geiger $M W$. Continuous infusion epidural analgesia during labor: a randomized, double-blind comparison of $0.0625 \%$ bupivacaine $/ 0.0002 \%$ fentanyl versus $0.125 \%$ bupivacaine. Anesthesiology 1988; 68: 754-9.

18 Badner NH, Bhandari $R$, Komar WE. Bupivacaine $0.125 \%$ improves continuous postoperative epidural fentanyl analgesia after abdominal or thoracic surgery. Can J Anaesth 1994; 41: 387-92.

19 Ferrante FM, Fanciullo GJ, Grichnik KP, Vaisman J, Sacks $G M$, Concepcion $M A$. Regression of sensory anesthesia during continuous epidural infusions of bupivacaine and opioid for total knee replacement. Anesth Analg 1993; 77: 1179-84.

20 Etches RC, Gammer T-L. Patient-controlled epidural meperidine with or without bupivacaine after thoracotomy (Letter). Reg Anesth 1995; $20: 4$.

21 Paech MJ, Moore JS, Evans SF. Meperidine for patientcontrolled analgesia after cesarean section. Intravenous versus epidural administration. Anesthesiology 1994; 80: 1268-76.

22 Tarnell RW, Polis T, Reid GN, Murphy $I L$, Penning JP. Patient-controlled analgesia with epidural meperidine after elective cesarean section. Reg Anesth 1992; 17: 329-33.

23 Ferrante FM, VadeBoncouer TR. Epidural analgesia with combinations of local anesthetics and opioids. In: Ferrante FM, VadeBoncouer TR (Eds.). Postoperative Pain Management. New-York: Churchill Livingstone, 1993: 305-33.

24 Etches RC, Gammer T-L, Cornish R. Patient-controlled epidural analgesia after thoracotomy: a comparison of meperidine with and without bupivacaine. Anesth Analg 1996; 83: 81-6.

25 Husemeyer RP, Davenport HT, Cummings AJ, Rosankiewicz JR. Comparison of epidural and intramuscular pethidine for analgesia in labour. $\mathrm{Br} \mathrm{J}$ Obstet Gynaecol 1981; 88: 711-7.

26 Perriss $B W$, Malins $A F$. Pain relief in labour using epidural pethidine with adrenaline. Anaesthesia 1981; 36: 631-3.

27 Husemeyer RP, Cummings AJ, Rosankiewicz JR, Davenport $H T$. A study of pethidine kinetics and analgesia in women in labour following intravenous, intra- muscular and epidural administration. $\mathrm{Br} \mathrm{J}$ Clin Pharmacol 1982; 13: 171-6.

28 Saissy JM, Taobane H, Dimou $M$, Atmani $M$, DrissiKamili N, Belamallem I. Analgésie péridurale thoracique à la péthidine après thoracotomie. Cah Anesthésiol 1985; 33: 497-500.

29 Badner NN, Reimer EJ, Komar WE, Moote CA. Lowdose bupivacaine does not improve postoperative epidural fentanyl analgesia in orthopedic patients. Anesth Analg 1991; 72: 337-41.

30 George KA, Wright PMC, Chisakuta A. Continuous thoracic epidural fentanyl for post-thoracotomy pain relief: with or without bupivacaine? Anaesthesia 1991; 46: 732-6.

31 Marcantonio ER, Juarez $G$, Goldman $L$, et al. The relationship of postoperative delirium with psychoactive medications. JAMA 1994; 272: 1518-22.

32 Cousins MJ, Mather LE, Glynn CJ, Wilson PR, Graham $J R$. Selective spinal analgesia (Letter). Lancet 1979; 1: 1141-2.

33 Glynn CJ, Mather LE, Cousins MJ, Grabam JR, Wilson $P R$. Peridural meperidine in humans: analgesic response, pharmacokinetics, and transmission into CSF Anesthesiology 1981; 55: 520-6.

34 Mather LE, Meffin PJ. Clinical pharmacokinetics pethidine. Clin Pharmacokin 1978; 3: 352-68.

35 Bromage PR, Pettigrew RT, Crowell DE. Tachyphylaxis in epidural analgesia. 1. Augmentation and decay of local anesthesia. J Clin Pharmacol 1969; 9: 30-8.

36 Renck $H$, Edström $H$, Kinnberger $B$, Brandt $G$. Thoracic epidural analgesia. II: Prolongation in the early postoperative period by continuous injection of 1.0\% bupivacaine. Acta Anaesthesiol Scand 1976; 20: 47-56.

37 Lund C, Mogensen T, Hjortsø N-C, Keblet H. Systemic morphine enhances spread of sensory analgesia during postoperative epidural bupivacaine infusion. Lancet $1985 ; 2: 1156-7$.

38 Hjortsø $N$-C, Lund C, Mogensen T, Bigler D, Keblet $H$. Epidural morphine improves pain relief and maintains sensory analgesia during continuous epidural bupivacaine after abdominal surgery. Anesth Analg 1986; 65: 1033-6.

39 Alon E, Niv D, Varrassi G, Heintz R. Nonsteroidal anti-inflammatory drugs in the control of postoperative pain. Pain Digest 1996; 6: 145-52. 